\title{
Life Cycle Analysis of Wind Turbine
}

\author{
Chaouki Ghenai \\ Ocean and Mechanical Engineering Department, Florida Atlantic University \\ USA
}

\section{Introduction}

The development of cleaner and efficient energy technologies and the use of new and renewable energy sources will play an important role in the sustainable development of a future energy strategy. The promotion of renewable sources of energy and the development of cleaner and more efficient energy systems are a high priority, for security and diversification of energy supply, environmental protection, and social and economic cohesion (International Energy Agency, 2006).

Sustainable energy is to provide the energy that meets the needs of the present without compromising the ability of future generations to meet their needs. Sustainable energy has two components: renewable energy and energy efficiency. Renewable energy uses renewable sources such biomass, wind, sun, waves, tides and geothermal heat. Renewable energy systems include wind power, solar power, wave power, geothermal power, tidal power and biomass based power. Renewable energy sources, such as wind, ocean waves, solar flux and biomass, offer emissions-free production of electricity and heat. For example, geothermal energy is heat from within the earth. The heat can be recovered as steam or hot water and use it to heat buildings or generate electricity. The solar energy can be converted into other forms of energy such as heat and electricity and wind energy is mainly used to generate electricity. Biomass is organic material made from plants and animals. Burning biomass is not the only way to release its energy. Biomass can be converted to other useable forms of energy, such as methane gas or transportation fuels, such as ethanol and biodiesel (clean alternative fuels). In addition to renewable energy, sustainable energy systems also include technologies that improve energy efficiency of systems using traditional non renewable sources. Improving the efficiency of energy systems or developing cleaner and efficient energy systems will slow down the energy demand growth, make deep cut in fossil fuel use and reduce the pollutant emissions. For examples, advanced fossil-fuel technologies could significantly reduce the amount of $\mathrm{CO} 2$ emitted by increasing the efficiency with which fuels are converted to electricity. Options for coal include integrated gasification combined cycle (IGCC) technology, ultra-supercritical steam cycles and pressurized fluidized bed combustion. For the transportation sector, dramatic reductions in $\mathrm{CO} 2$ emissions from transport can be achieved by using available and emerging energy-saving vehicle technologies and switching to alternative fuels such as biofuels (biodiesel, ethanol). For industrial applications, making greater use of waste heat, generating electricity on-site, and putting in place more efficient processes and equipment could minimize external energy demands from industry. Advanced process control and greater reliance on biomass 
and biotechnologies for producing fuels, chemicals and plastics could further reduce energy use and $\mathrm{CO} 2$ emissions. Energy use in residential and commercial buildings can be substantially reduced with integrated building design. Insulation, new lighting technology and efficient equipment are some of the measures that can be used to cut both energy losses and heating and cooling needs. Solar technology, on-site generation of heat and power, and computerized energy management systems within and among buildings could offer further reductions in energy use and $\mathrm{CO} 2$ emissions for residential and commercial buildings.

This Chapter will focus on wind energy. Electric generation using wind turbines is growing very fast. Wind energy is a clean and efficient energy system but during all stages (primary materials production, manufacturing of wind turbine parts, transportation, maintenance, and disposal) of wind turbine life cycle energy was consumed and carbon dioxide $\mathrm{CO} 2 \mathrm{can}$ be emitted to the atmosphere. What is the dominant phase of the wind turbine life that is consuming more energy and producing more emissions? What can be done during the design process to reduce the energy consumption and carbon foot print for the wind turbine life cycle? The first part of this chapter will include a brief history about the wind energy, the fundamental concepts of wind turbine and wind turbine parts. The second part will include a life cycle analysis of wind turbine to determine the dominant phase (material, manufacturing, use, transportation, and disposal) of wind turbine life that is consuming more energy and producing more $\mathrm{CO} 2$ emissions.

\section{Wind energy}

The use of wind as an energy source begins in antiquity. Mankind was using the wind energy for sailing ships and grinding grain or pumping water. Windmills appear in Europe back in $12^{\text {th }}$ century. Between the end of nineteenth and beginning of twentieth century, first electricity generation was carried out by windmills with $12 \mathrm{KW}$. Horizontal-axis windmills were an integral part of the rural economy, but it fell into disuse with the advent of cheap fossil-fuelled engines and then the wide spread of rural electrification. However, in twentieth century there was an interest in using wind energy once electricity grids became available. In 1941, Smith-Putnam wind turbine with power of 1.25 MW was constructed in USA. This remarkable machine had a rotor $53 \mathrm{~m}$ in diameter, full-span pitch control and flapping blades to reduce the loads. Although a blade spar failed catastrophically in 1945, it remains the largest wind turbine constructed for some 40 years (Acker and Hand, 1999). International oil crisis in 1973 lead to re-utilization of renewable energy resources in the large scale and wind power was among others. The sudden increase in price of oil stimulated a number of substantial government-funded programs of research, development and demonstration. In 1987, a wind turbine with a rotor diameter of $97.5 \mathrm{~m}$ with a power of $2.5 \mathrm{MW}$ was constructed in USA. However, it has to be noted that the problems of operating very large wind turbines, in difficult wind climates were underestimated. With considerable state support, many private companies were constructing much smaller wind turbines for commercial sales. In particular, California in the mid-1980's resulted in the installation of very large number of quite small (less than $100 \mathrm{KW}$ ) wind turbines. Being smaller they were generally easy to operate and also repair or modify. The use of wind energy was stimulated in 1973 by the increase of price of fossil-fuel and of course, the main driver of wind turbines was to generate electrical power with very low $\mathrm{CO}_{2}$ emissions to help limit the climate change. In 1997 the Commission of the European Union was calling for 12 percent of the 
gross energy demand of the European Union to be contributed from renewable by 2010. In the last 25 years the global wind energy had been increasing drastically and at the end of 2009 total world wind capacity reached 159,213 MW. Wind power showed a growth rate of $31.7 \%$, the highest rate since 2001 . The trend continued that wind capacity doubles every three years. The wind sector employed 550,000 persons worldwide.

In the year 2012, the wind industry is expected for the first time to offer 1 million jobs. The USA maintained its number one position in terms of total installed capacity and China became number two in total capacity, only slightly ahead of Germany, both of them with around 26,000 Megawatt of wind capacity installed. Asia accounted for the largest share of new installations (40.4 \%), followed by North America $(28.4 \%)$ and Europe fell back to the third place $(27.3 \%)$. Latin America showed encouraging growth and more than doubled its installations, mainly due to Brazil and Mexico. A total wind capacity of 203,000 Megawatt will be exceeded within the year 2010. Based on accelerated development and further improved policies, world wide energy association WWEA increases its predictions and sees a global capacity of 1,900,000 Megawatt as possible by the year 2020 (World Wide Energy Association report, 2009). The world's primary energy needs are projected to grow by $56 \%$ between 2005 and 2030, by an average annual rate of 1.8\% per year (European Wind Energy Agency, 2006)

\subsection{Fundamental concept of wind turbine}

A wind turbine is a rotary device that extracts the energy from the wind. The mechanical energy from the wind turbine is converted to electricity (wind turbine generator). The wind turbine can rotate through a horizontal (horizontal axis wind turbine - HAWT) or vertical (VAWT) axis. Most of the modern wind turbines fall in these two basic groups: HAWT and VAWT. For the HAWT, the position of the turbine can be either upwind or downwind. For the horizontal upwind turbine, the wind hits the turbine blade before it hits the tower. For the horizontal downwind turbine, the wind hits the tower first. The basic advantages of the vertical axis wind turbine are (1) the generator and gear box can be placed on the ground and (2) no need of a tower. The disadvantages of the VAWT are: (1) the wind speeds are very low close to ground level, so although you may save a tower, the wind speeds will be very low on the lower part of the rotor, and (2) the overall efficiency of the vertical axis wind turbine is not impressive (Burton et al., 2001). The main parts of a wind turbine parts (see Figure 1) are:

- Blades: or airfoil designed to capture the energy from the strong and fast wind. The blades are lightweight, durable and corrosion-resistant material. The best materials are composites of fiberglass and reinforced plastic.

- Rotor: designed to capture the maximum surface area of wind. The rotor rotates around the generator through the low speed shaft and gear box.

- Gear Box: A gear box magnifies or amplifies the energy output of the rotor. The gear box is situated directly between the rotor and the generator.

- Generator: The generator is used to produce electricity from the rotation of the rotor. Generators come in various sizes, relative to the desired power output.

- Nacelle: The nacelle is an enclosure that seals and protects the generator and gear box from the other elements. 
- $\quad$ Tower: The tower of the wind turbine carries the nacelle and the rotor. The towers for large wind turbines may be either tubular steel towers, lattice towers, or concrete towers. The higher the wind tower, the better the wind. Winds closer to the ground are not only slower, they are also more turbulent. Higher winds are not corrupted by obstructions on the ground and they are also steadier.

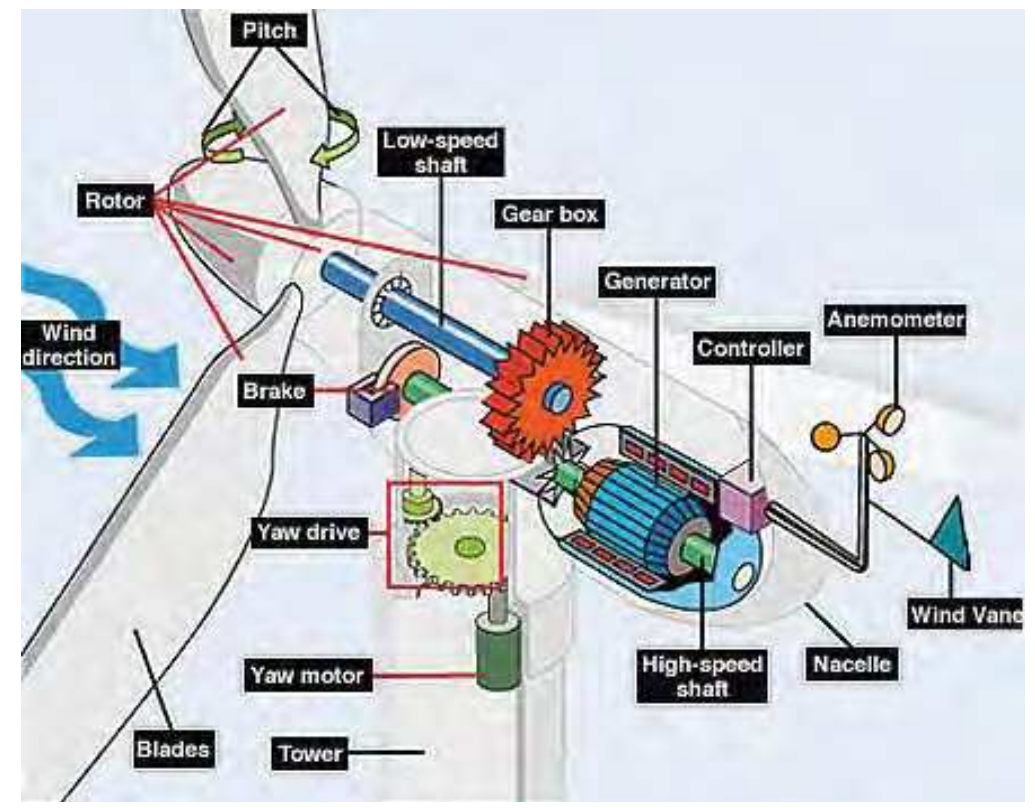

Fig. 1. Wind turbine parts

\subsection{Wind turbine design}

During the design of wind turbines, the strength, the dynamic behavior, and the fatigue properties of the materials and the entire assembly need to be taken into consideration. The wind turbines are built to catch the wind's kinetic energy. Modern wind turbines are not built with a lot of rotor blades. Turbines with many blades or very wide blades will be subject to very large forces, when the wind blows at high speed. The energy content of the wind varies with the third power of the wind speed. The wind turbines are built to withstand extreme winds. To limit the influence of the extreme winds and to let the turbines rotates relatively quickly it is generally prefer to build turbines with a few, long, narrow blades.

- Fatigue Loads (forces): If the wind turbines are located in a very turbulent wind climate, they are subject to fluctuating winds and hence fluctuating forces. The components of the wind turbine such as rotor blades with repeated bending may develop cracks which ultimately may make the component break. When designing a wind turbine it is important to calculate in advance how the different components will vibrate, both individually, and jointly. It is also important to calculate the forces involved in each bending or stretching of a component (structural dynamics). 
- Upwind/Downwind wind turbines designs: The upwind wind turbines have the rotor facing the wind. The basic advantage of upwind designs is that one avoids the wind shade behind the tower. By far the vast majority of wind turbines have this design. The downwind wind turbines have the rotor placed on the lee side of the tower.

- Number of blades: Most modern wind turbines are three-bladed designs with the rotor position maintained upwind using electrical motors in their yaw mechanism. The vast majority of the turbines sold in world markets have this design. The two-bladed wind turbine designs have the advantage of saving the cost of one rotor blade and its weight. However, they tend to have difficulty in penetrating the market, partly because they require higher rotational speed to yield the same energy output.

- Mechanical and aerodynamics noise: sound emissions from wind turbines may have two different origins: Mechanical noise and aerodynamic noise. The mechanical noise originates from metal components moving or knocking against each other may originate in the gearbox, in the drive train (the shafts), and in the generator of a wind turbine. Sound insulation can be useful to minimise some medium- and high-frequency noise. In general, it is important to reduce the noise problems at the source, in the structure of the machine itself. The source of the aerodynamic sound emission is when the wind hits different objects at a certain speed, it will generally start making a sound. For example, rotor blades make a slight swishing sound at relatively low wind speeds. Careful design of trailing edges and very careful handling of rotor blades while they are mounted, have become routine practice in the industry.

\subsection{Wind farm}

Commercial wind farms are constructed to generate electricity for sale through the electric power grid. The number of wind turbines on a wind farm can vary greatly, ranging from a single turbine to thousands. Large wind farms typically consist of multiple large turbines located in flat, open land. Small wind farms, such as those with one or two turbines, are often located on a crest or hill. The size of the turbines can vary as well, but generally they are in the range of 500 Kilowatts to several Megawatts, with 4.5 Megawatts being about the largest. Physically, they can be quite large as well, with rotor diameters ranging from $30 \mathrm{~m}$ to $120 \mathrm{~m}$ and tower heights ranging from $50 \mathrm{~m}$ to $100 \mathrm{~m}$. The top ten wind turbine manufacturers, as measured by global market share in 2007 are listed in Table 1. Due to advances in manufacturing and design, the larger turbines are becoming more common. In general, a one Megawatt unit can produce enough electricity to meet the needs of about 100200 average homes. A large wind farm with many turbines can produce many times that amount. However, with all commercial wind farms, the power that is generated first flows into the local electric transmission grid and does not flow directly to specific homes.

\subsection{Wind turbine power}

The Wind turbines work by converting the kinetic energy in the wind first into rotational kinetic energy in the turbine and then electrical energy. The wind power available for conversion mainly depends on the wind speed and the swept area of the turbine:

$$
P_{W}=\frac{1}{2} \rho A V^{3}
$$




\begin{tabular}{|c|c|c|c|c|c|}
\hline \multirow[b]{2}{*}{1} & \multirow[b]{2}{*}{ Vestas } & \multirow{2}{*}{$\begin{array}{l}\text { Model } \\
\text { V90 }\end{array}$} & \multicolumn{3}{|c|}{ Power rating $[\mathrm{kW}]$ Diameter $[\mathrm{m}]$ Tip speed $[\mathrm{m} / \mathrm{s}]$} \\
\hline & & & 3,000 & 90 & 87 \\
\hline 2 & $\begin{array}{c}\text { GE } \\
\text { Energy }\end{array}$ & $2.5 \mathrm{XL}$ & 2,500 & 100 & 86 \\
\hline 3 & Gamesa & G90 & 2,000 & 90 & 90 \\
\hline 4 & Enercon & E82 & 2,000 & 82 & 84 \\
\hline 5 & Suzlon & S88 & 2,100 & 88 & 71 \\
\hline 6 & Siemens & $3.6 \mathrm{SWT}$ & 3,600 & 107 & 73 \\
\hline 7 & Acciona & AW-119/3000 & 3,000 & 116 & 74.7 \\
\hline 8 & Goldwind & REpower750 & 750 & 48 & 58 \\
\hline 9 & Nordex & N100 & 2,500 & 99.8 & 78 \\
\hline 10 & Sinovel & 1500 (Windtec) & 1,500 & 70 & \\
\hline
\end{tabular}

Table 1. Top ten wind commercial wind turbines manufactures in 2007

Where $\rho$ is the air density $\left(\mathrm{Kg} / \mathrm{m}_{3}\right), A$ is the swept area $\left(\mathrm{m}_{2}\right)$ and $V$ the wind speed $(\mathrm{m} / \mathrm{s})$. Albert Betz (German physicist) concluded in 1919 that no wind turbine can convert more than $16 / 27$ (59.3\%) of the kinetic energy of the wind into mechanical energy turning a rotor (Betz Limit or Betz). The theoretical maximum power efficiency of any design of wind turbine is 0.59 (Hau, 2000 and Hartwanger and Horvat, 2008). No more than 59\% of the energy carried by the wind can be extracted by a wind turbine. The wind turbines cannot operate at this maximum limit. The power coefficient $C_{p}$ needs to be factored in equation (1) and the extractable power from the wind is given by:

$$
P=\frac{1}{2} C_{P} \rho A V^{3}
$$

The $\mathrm{Cp}$ value is unique to each turbine type and is a function of wind speed that the turbine is operating in. In real world, the value of $C_{p}$ is well below the Betz limit (0.59) with values of $0.35-0.45$ for the best designed wind turbines. If we take into account the other factors in a complete wind turbine system (gearbox, bearings, generator), only $10-30 \%$ of the power of the wind is actually converted into usable electricity. The power coefficient $C_{p}$, defined as that the power extracted by rotor to power available in the wind is given by:

$$
C_{p}=\frac{P}{\frac{1}{2} \rho A V^{3}}=\frac{\text { Power Extracted by Rotor }}{\text { Power Available in the Wind }}
$$

\section{Life cycle analysis and selections strategies for guiding design}

The material life cycle is shown in Figure 2. Ore and feedstock, drawn from the earth's resources, are processed to give materials. These materials are manufactured into products that are used, and, at the end of their lives, discarded, a fraction perhaps entering a recycling loop, the rest committed to incineration or land-fill. Energy and materials are consumed at each point in this cycle (phases), with an associated penalty of $\mathrm{CO} 2$, SOx, NOx and other emissions, heat, and gaseous, liquid and solid waste. These are assessed by the technique of 
life-cycle analysis (Ashby, 2005, Ashby et al., 207, Granta Design, 20090). The steps for life cycale analysis are:

1. Define the goal and scope of the assessment: Why do the assessment? What is the subject and which bit (s) of its life are assessed?

2. Compile an inventory of relevant inputs and outputs: What resources are consumed? (bill of materials) What are the emissions generated?

3. Evaluate the potential impacts associated with those inputs and outputs

4. Interpretation of the results of the inventory analysis and impact assessment phases in relation of the objectives of the study: What the result means? What is to be done about them?

The life cycle analysis studies examine energy and material flows in raw material acquisition; processing and manufacturing; distribution and storage (transport, refrigeration...); use; maintenance and repair; and recycling options (Gabi, 2008, Graedel, 1998, and Fiksel, 2009).

The eco audit or life cycle analyis and selection strategies for guiding the design are:

The first step is to develop a tool that is approximate but retains sufficient discrimination to differentiate between alternative choices. A spectrum of levels of analysis exist, ranging from a simple eco-screening against a list of banned or undesirable materials and processes to a full LCA, with overheads of time and cost.

The second step is to select a single measure of eco-stress. On one point there is some international agreement: the Kyoto Protocol committed the developed nations that signed it to progressively reduce carbon emissions, meaning CO2 (Kyoto Protocol, 1997). At the national level the focus is more on reducing energy consumption, but since this and $\mathrm{CO} 2$ production are closely related, they are nearly equivalent. Thus there is certain logic in basing design decisions on energy consumption or $\mathrm{CO} 2$ generation; they carry more conviction than the use of a more obscure indicator. We shall follow this route, using energy as our measure. The third step is to separate the contributions of the phases of life because subsequent action depends on which is the dominant one. If it is that a material production, then choosing a material with low "embodied energy" is the way forward. But if it is the use phase, then choosing a material to make use less energy-intensive is the right approach, even if it has a higher embodied energy.

For selection to minimize eco-impact we must first ask: which phase of the life cycle of the product under consideration makes the largest impact on the environment? The answer guides material selection. To carry out an eco-audit we need the bill of material, shaping or manufacturing process, transportation used of the parts of the final product, the duty cycle during the use of the product, and also the eco data for the energy and $\mathrm{CO} 2$ footprints of materials and manufacturing process.

The Life-Cycle Analysis has now become a vital sustainable development tool. It enables the major aspects of a product's environmental impact to be targeted, prioritization of any improvements to be made to processes, and a comparison of two products with the same function on the basis of their environmental profiles. 


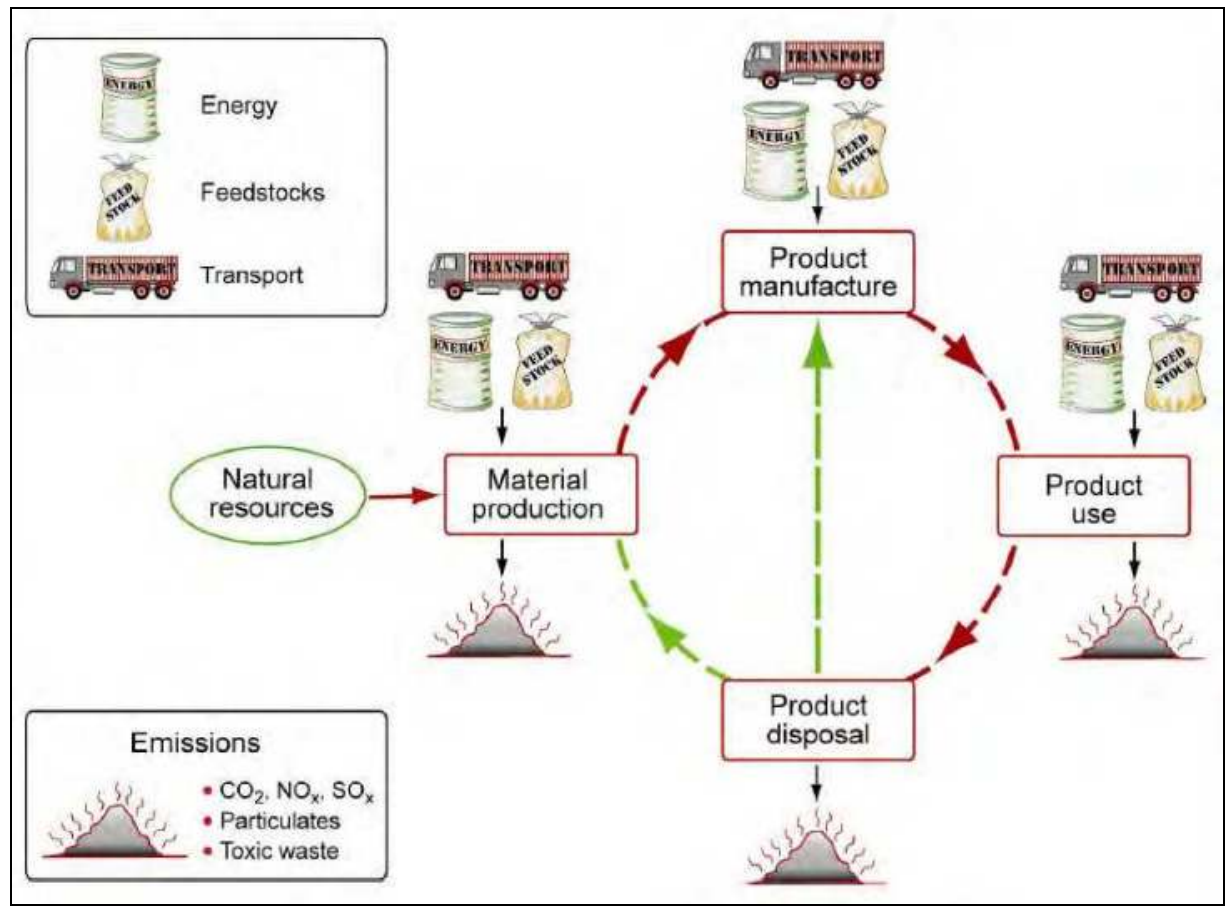

Fig. 2. Material Life cycle analysis

\section{Results: Life cycle analysis of $2.0 \mathrm{MW}$ wind turbine}

Life cycle analysis (LCA) of 2.0 MW wind turbine is presented in this chapter. The LCA addresses the energy use and carbon foot print for the five phases (materials, manufacturing, transportation, use and disposal) through the product life cycle (Martinnez et al., 2009 and Nalukowe et al., 2006). Power generation from wind turbine is a renewable and sustainable energy but in a life cycle perspective wind turbines consumes energy resources and causes emissions during the production of raw materials, manufacturing process, its use, transportation and disposal. In order to determine the impacts of power generation using wind turbine, all components needed for the production of electricity should be include in the analysis including the tower, nacelle, rotor, foundation and transmission.

The bill of materials for a 2 MW land-based turbine (Elsam Engineering, 2004, Nordex, 2004, and Visat, 2005) is listed in Table 2. Some energy is consumed during the turbine's life (expected to be 25 years), mostly in primary materials production, manufacturing processes, and transport associated with maintenance. The energy for the transportation of small and large parts of the wind turbine and the nergy used for maintenace was calculated from information on inspection and service visits in the Vestas report (Elsam Engineering, 2004, Nordex, 2004, and Visat, 2005) and estimates of distances travelled (entered under "Static" use mode as $200 \mathrm{hp}$ used for 2 hours 3 days per year). The manufacturing process for the wind turbine parst are summarized in Table 3. 


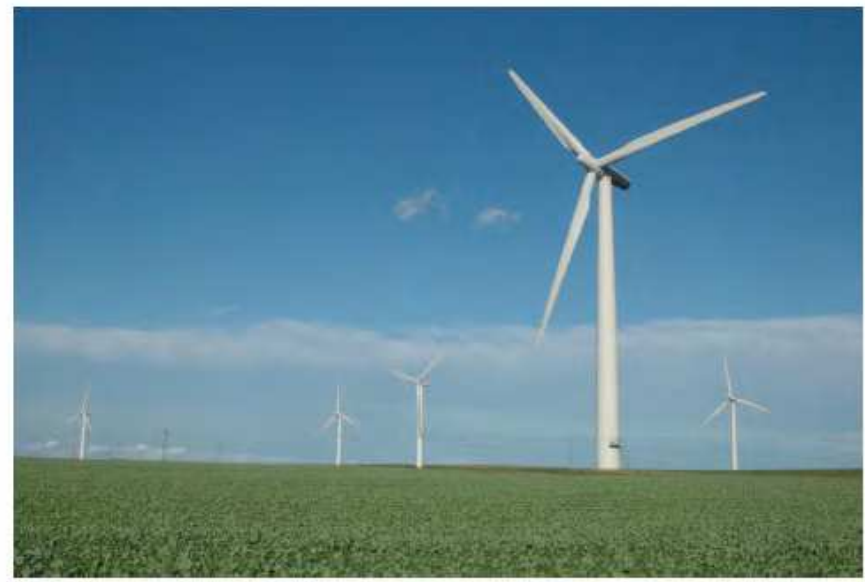

\begin{tabular}{|c|c|c}
\hline Component & Material & Total Mass (kg) \\
\hline Tower structure & Low carbon steel & 164000.000 \\
\hline Tower, Cathodic Protection & Zinc alloys & 203.000 \\
\hline Nacelle, gears & Stainless steel & 19000.000 \\
\hline Nacelle, generator core & Cast iron, gray & 9000.000 \\
\hline Nacelle, generator conductors & Copper & 1000.000 \\
\hline Nacelle, transformer core & Cast iron, gray & 6000.000 \\
\hline Nacelle, transformer conductors & Copper & 2000.000 \\
\hline Nacelle, transformer conductors & Aluminum alloys & 1700.000 \\
\hline Nacelle, cover & GFRP, epoxy matrix (isotropic) & 4000.000 \\
\hline Nacelle, main shaft & Cast iron, ductile (nodular) & 12000.000 \\
\hline Nacelle, other forged components & Stainless steel & 3000.000 \\
\hline Nacelle, other cast components & Cast iron, ductile (nodular) & 4000.000 \\
\hline Rotor, blades & CFRP, epoxy matrix (isotropic) & 24500.000 \\
\hline Rotor, iron components & Cast iron, ductile (nodular) & 2000.000 \\
\hline Rotor, spinner & GFR, epoxy matrix (isotropic) & 3000.000 \\
\hline Rotor, spinner & Cast iron, ductile (nodular) & 2200.000 \\
\hline Foundations, pile \& platform & Concrete & 805000.000 \\
\hline Foundations, steel & Low carbon steel & 27000.000 \\
\hline Transmission, conductors & Aluminum alloys & 254.000 \\
\hline Transmission, conductors & Copper & 72.000 \\
\hline Transmission, insulation & $1.091 \mathrm{E}+006$ \\
\hline
\end{tabular}

Table 2. Bill of Materials for the $2 \mathrm{MW}$ Wind Turbines 


\begin{tabular}{|c|c|}
\hline Component & Manufacturing Process \\
\hline Tower structure & Forging, rolling \\
\hline Tower, Cathodic Protection & Casting \\
\hline Nacelle, gears & Forging, rolling \\
\hline Nacelle, generator core & Forging, rolling \\
\hline Nacelle, generator conductors & Forging, rolling \\
\hline Nacelle, transformer core & Forging, rolling \\
\hline Nacelle, transformer conductors - Copper & Forging, rolling \\
\hline Nacelle, transformer conductors - Aluminum & Forging, rolling \\
\hline Nacelle, cover & Composite forming \\
\hline Nacelle, main shaft & Casting \\
\hline Nacelle, other forged components & Forging, rolling \\
\hline Nacelle, other cast components & Casting \\
\hline Rotor, blades & Composite forming \\
\hline Rotor, iron components & Casting \\
\hline Rotor, spinner & Composite forming \\
\hline Rotor, spinner & Casting \\
\hline Foundations, pile \& platform & Construction \\
\hline Foundations, steel & Forging, rolling \\
\hline Transmission, conductors - Copper & Forging, rolling \\
\hline Transmission, conductors - Aluminum & Forging, rolling \\
\hline Transmission, insulation & Polymer extrusion \\
\hline
\end{tabular}

Table 3. Manufacturing Processes

The net energy demands of each phase of life are summarized in Figure 3. The life cycle analysis was performed first without recycled wind turbine materials sent to landfill). The second analysis was performed with recycled wind turbine materials (the wind turbine materials that can be recycled were sent to recycling at the end life of the wind turbine). Figure 3 and Table 4 show clearly that the dominant phase that is consuming more energy and produccing more $\mathrm{CO} 2$ emisions is the material phase. More energy is consumed and high amount of $\mathrm{CO} 2$ is released in the atmosphere during the primary material production of the wind turbine parts. The second dominant phase is the manufacuring process when the parts of turbine are sent to landfill at the end life of the turbine. The results also show the benefits of recycling the materials at the end life of the wind turbine. If all the materials are sent to landfill at the end of life of the wind turbine, $2.18 \mathrm{E}+011 \mathrm{~J}$ of energy ( $1.1 \%$ of the total energy) is needed to process these materials and $13095.71 \mathrm{Kg}$ of $\mathrm{CO} 2(0.9 \%$ increase of the total CO2) are released to the atmosphere at the end of life of the turbine. If the material of the wind turbine are recycled, a total energy of $6.85 \mathrm{E}+012 \mathrm{~J}$ representing $54.8 \%$ of the total energy is recovered at the end life of the material. A net reduction of C02 emissions by $495917.28 \mathrm{Kg}(55.4 \%$ of the total $\mathrm{CO} 2$ emission) is obtained by recycling the wind turbine material (see Table 4 ). 

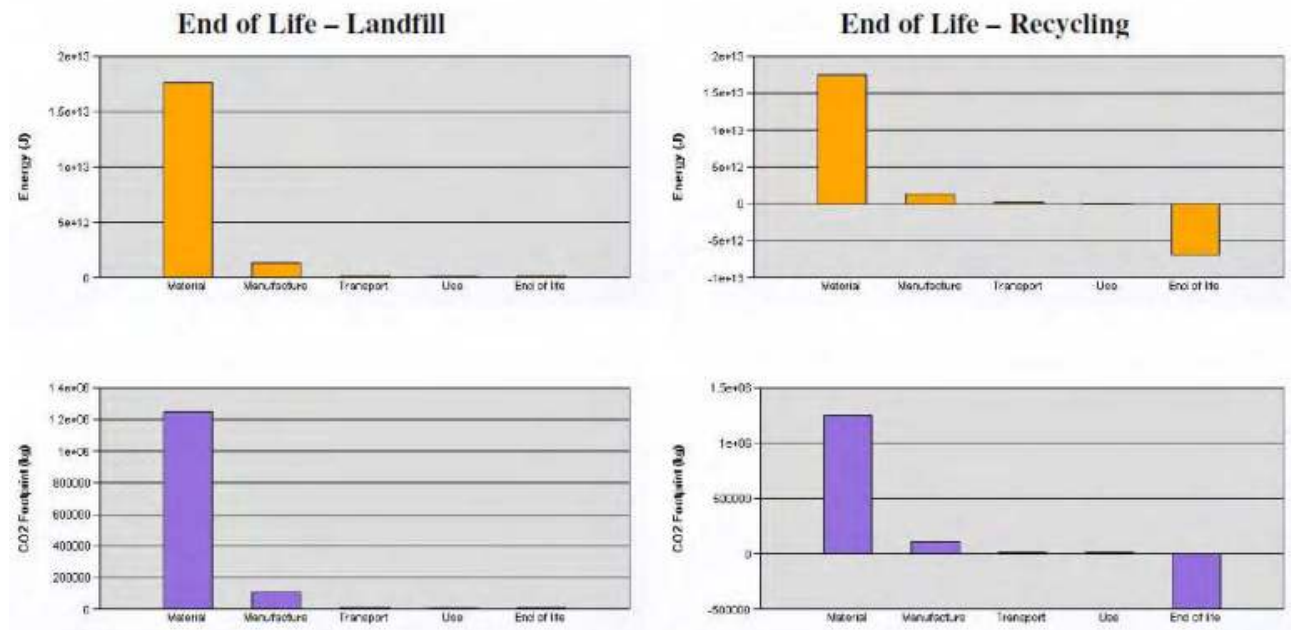

Fig. 3. Life Cycle Analysis of Wind Turbine - With and Without Wind Turbine Material Recycling

\begin{tabular}{|l|c|c|}
\hline \multicolumn{3}{|c|}{ End of Life - Landfill } \\
\hline Phase & Energy $(\mathbf{J})$ & $\mathbf{C O 2}(\mathbf{k g})$ \\
\hline Material & $1.7594 \mathrm{E}+013$ & $1.2546 \mathrm{E}+006$ \\
\hline Manufacture & $1.3593 \mathrm{E}+012$ & 107669.7209 \\
\hline Transport & $2.4336 \mathrm{E}+011$ & 17278.6954 \\
\hline Use & $1.6778 \mathrm{E}+011$ & 11912.5577 \\
\hline End of life & $2.1826 \mathrm{E}+011$ & 13095.7080 \\
\hline Total & $\mathbf{1 . 9 5 8 3 E}+\mathbf{0 1 3}$ & $\mathbf{1 . 4 0 4 5 E}+\mathbf{0 0 6}$ \\
\hline
\end{tabular}

\begin{tabular}{|l|c|c|}
\hline \multirow{3}{*}{$\begin{array}{l}\text { Ehase } \\
\text { Material }\end{array}$} & End of Life - Recycling \\
\cline { 2 - 3 } Manufacture & Energy $(\mathbf{J})$ & $\mathbf{C O 2}(\mathbf{k g})$ \\
\cline { 2 - 3 } Transport & $1.7594 \mathrm{E}+013$ & $1.2546 \mathrm{E}+006$ \\
\cline { 2 - 3 } Use & $1.3593 \mathrm{E}+012$ & 107669.7209 \\
\cline { 2 - 3 } End of life & $2.4336 \mathrm{E}+011$ & 17278.6954 \\
\cline { 2 - 3 } Total & $1.6778 \mathrm{E}+011$ & 11912.5577 \\
\cline { 2 - 3 } & $-6.8512 \mathrm{E}+012$ & -495917.2797 \\
\cline { 2 - 3 } & $\mathbf{1 . 2 5 1 3 E}+\mathbf{0 1 3}$ & $\mathbf{8 9 5 5 0 3 . 8 9 0 6}$ \\
\hline
\end{tabular}

Table 4. Energy and CO2 Footprint Summary - Wind Turbine 


\begin{tabular}{|c|c|c|}
\hline & $\begin{array}{c}\text { End of life } \\
\text { landfill }\end{array}$ & $\begin{array}{c}\text { End of life } \\
\text { Recycling }\end{array}$ \\
\hline Total Construction Energy $(\mathrm{J})$ & $1.9510^{13}$ & $1.2510^{13}$ \\
\hline TCE - Total Construction Energy $(\mathrm{kWhr})$ & $5.4110^{6}$ & $3.4710^{6}$ \\
\hline AEO - Annual Energy Output with 40\% capacity factor $(\mathrm{kWhr} / \mathrm{year})$ & $7.010^{6}$ & $7.010^{6}$ \\
\hline TE - Total Energy for the 25 years life of the turbine $(\mathrm{kWhr})$ & $17510^{6}$ & $17510^{6}$ \\
\hline TE/TCE - Total Energy Generated by the Turbine / Total Construction Energy & 32.32 & 50.43 \\
\hline EPBT = TCE/AEO Energy Pay back Time (months) & 9.27 & 5.94 \\
\hline
\end{tabular}

Table 5. Construction Energy, Wind Turbine Energy Output and Energy Pay Back Time

The turbine is rated at $2 \mathrm{MW}$ but it produces this power only with the right wind conditions. In a best case scenario the turbine runs at an average capacity factor of $40 \%$ giving an annual energy output of $7.0 \times 10^{6} \mathrm{kWhr} /$ year. The total energy generated by the turbine over a 25 year life is $175 \times 10^{6} \mathrm{kWhr}$ (see Table 5). The total energy generated by the turbine over 25 year life time is about 32.32 times the energy required to build and service it ( $\left.5.4110^{6} \mathrm{kWhr}\right)$ if the turbine materials are sent to landfill at the end of life of the turbine. If the materials are recycled, the total energy generated by the turbine over 25 year life time is about 50.43 times the energy required to build and service it $\left(3.4710^{6} \mathrm{kWhr}\right)$. With a wind turbine capacity factor of $40 \%$, the energy payback time is about 9.27 months if the wind turbine materials are sent to landfill at the end life of the turbine and is only 5.94 months if the materials are recycled. The results show clearly the benefits of recycling parts of the wind turbine at the end life of the turbine.

\section{Conclusions}

The development of cleaner and efficient energy technologies and the use of new and renewable energy sources will play an important role in the sustainable development of a future energy strategy. Power generation from wind turbine is a renewable and sustainable energy but in a life cycle perspective wind turbines consumes energy resources and causes emissions during the production of raw materials, manufacturing process, transportation of small and large parts of the wind turbines, maintenance, and disposal of the parts at the end life of the turbines. To determine the impacts of power generation using wind turbine, all components needed for the production of electricity should be include in the analysis including the tower, nacelle, rotor, foundation and transmission.

In eco aware wind turbine design, the materials are energy intensive with high embodies energy and carbon foot print, the material choice impacts the energy and $\mathrm{CO} 2$ for the manufacturing process, the material impacts the weight of the product and its thermal and electric characteristics and the energy it consumes during the use; and the material choice also impacts the potential for recycling or energy recovery at the end of life. The eco aware wind turbine design has two-part strategy: (1) Eco Audit: quick and approximate assessment of the distribution of energy demand and carbon emission over a product's life; and (2) material selection to minimize the energy and carbon over the full life, balancing the influence of the choice over each phase of the life (selection strategies and eco informed material selection). 
The results of life cycle analysis of the 2.0 MW wind turbine show the problem with the energy consumed and carbon foot print was for the material phase. More energy and more emissions are produced during the primary material production of the wind turbine parts. The manufacturing process is the second dominant phase. The energy consumption and carbon foot print are negligible for the transportation and the use phases. The results also show clearly the benefits of recycling the wind turbine parts at the end of life. The life cycle analysis of the $2.0 \mathrm{MW}$ wind turbine show that $54.8 \%$ of the total energy is recovered and a net reduction of $\mathrm{C} 02$ emissions by $55.4 \%$ is obtained by recycling the wind turbine materials at the end of life of the wind turbine.

\section{References}

Acker, T.; Hand, M., (1999), “Aerodynamic Performance of the NREL Unsteady Aerodynamics Experiment (Phase IV) Twisted Rotor", AIAA-99-0045, Prepared for the 37th AIAA Aerospace Sciences Meeting and Exhibit, Reno, NV, January 11-14, p. $211-221$.

Ashby, M.F., (2005) "Materials Selection in Mechanical Design", 3rd edition, ButterworthHeinemann, Oxford, UK, Chapter 16

Ashby, M.F. Shercliff, H. and Cebon, D., (2007), "Materials: engineering, science, processing and design", Butterworth Heinemann, Oxford UK, Chapter 20.

Burton T., Sharpe D., Jenkins N. and Bossanyi E, (2001), Wind Energy Handbook, John Wiley \& Sons Ltd: Chichester.

European Wind Energy Agency, VV.AA. Annual report. Technical report, EWEA, European Wind Energy Agency, 2006

Fiksel, J., Design for Envirnment, (2009), A guide to sustianble product development, McGraw Hill, ISBN 978-0-07-160556-4

Gabi, PE International, (2008), www.gabi-sofwtare.com

Graedel, T.E., (1998), Streamlined life cycle assessment, prentice Hall, ISBN 0-13-607425-1

Granta Design Limited, Cambridge, (2009) (www.grantadesign.com), CES EduPack User Guide

Hartwanger, D. and Horvat, (2008), A., 3D Modeling of a wind turbine using CFD, NAFEMS UK Conference, Cheltenham, United of Kingdom, June 10-11, 2008

Hau E, (2000), Wind turbines. Springer: Berlin.

Elsam Engineering A/S, (2004) “Life Cycle Assessment of Offshore and Onshore Sited Wind Farms", Report by Vestas Wind Systems A/S of the Danish Elsam Engineering

International Energy Agency, VV.AA, (2006), Wind energy annual report, Technical report, IEA, International Energy Agency.

Kyoto protocol, United Nations, Framework Convention on Climate Change, (1997), Document FCCC/CP 1997/7/ADD.1

Martinnez E., Sanz, F., Pellegrini, s., Jimenez e., Blanco, j., (2009), Life cycle assessment of a multi-megawatt wind turbine, Renewable Energy 34 (2009) 667-673

Nalukowe B.B., Liu, J., Damien, W., and Lukawski, T., (2006), Life Cycle Assessment of a Wind Turbine, Report 1N1800

Nordex N90 Technical Description, Nordex Energy (2004) 
Vestas (2005) "Life cycle assessment of offshore and onshore sited wind turbines" Vestas

Wind Systems A/S, Alsvij 21, 8900 Randus, Denmark (www.vestas.com) 


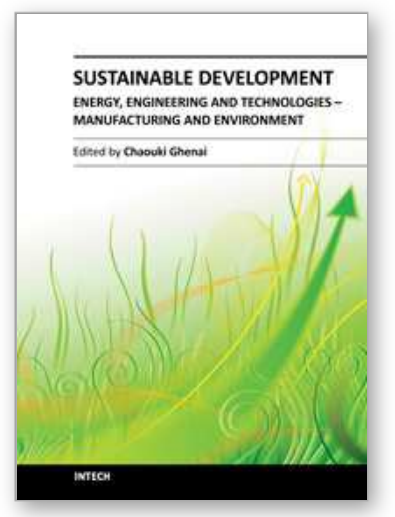

\author{
Sustainable Development - Energy, Engineering and Technologies \\ - Manufacturing and Environment \\ Edited by Prof. Chaouki Ghenai
}

ISBN 978-953-51-0165-9

Hard cover, 264 pages

Publisher InTech

Published online 29, February, 2012

Published in print edition February, 2012

The technological advancement of our civilization has created a consumer society expanding faster than the planet's resources allow, with our resource and energy needs rising exponentially in the past century. Securing the future of the human race will require an improved understanding of the environment as well as of technological solutions, mindsets and behaviors in line with modes of development that the ecosphere of our planet can support. Some experts see the only solution in a global deflation of the currently unsustainable exploitation of resources. However, sustainable development offers an approach that would be practical to fuse with the managerial strategies and assessment tools for policy and decision makers at the regional planning level. Environmentalists, architects, engineers, policy makers and economists will have to work together in order to ensure that planning and development can meet our society's present needs without compromising the security of future generations.

\title{
How to reference
}

In order to correctly reference this scholarly work, feel free to copy and paste the following:

Chaouki Ghenai (2012). Life Cycle Analysis of Wind Turbine, Sustainable Development - Energy, Engineering and Technologies - Manufacturing and Environment, Prof. Chaouki Ghenai (Ed.), ISBN: 978-953-51-0165-9, InTech, Available from: http://www.intechopen.com/books/sustainable-development-energy-engineering-andtechnologies-manufacturing-and-environment/life-cycle-analysis-of-wind-turbine-

\section{INTECH}

open science | open minds

\author{
InTech Europe \\ University Campus STeP Ri \\ Slavka Krautzeka 83/A \\ 51000 Rijeka, Croatia \\ Phone: +385 (51) 770447 \\ Fax: +385 (51) 686166 \\ www.intechopen.com
}

\author{
InTech China \\ Unit 405, Office Block, Hotel Equatorial Shanghai \\ No.65, Yan An Road (West), Shanghai, 200040, China \\ 中国上海市延安西路65号上海国际贵都大饭店办公楼 405 单元 \\ Phone: +86-21-62489820 \\ Fax: $+86-21-62489821$
}


(C) 2012 The Author(s). Licensee IntechOpen. This is an open access article distributed under the terms of the Creative Commons Attribution 3.0 License, which permits unrestricted use, distribution, and reproduction in any medium, provided the original work is properly cited. 